\title{
CORRECTION
}

View Article Online

View Journal | View Issue

Check for updates

Cite this: New J. Chem., 2020, 44, 16247

DOI: $10.1039 /$ d0nj90132f

rsc.li/njc

The authors regret that Fig. 1B was incorrect in the original manuscript. The correct version of Fig. 1B is published here.

\section{Correction: Catalytic transfer hydrogenation of biomass-derived levulinic acid to $\gamma$-valerolactone over Sn/Al-SBA-15 catalysts}

\author{
Sakthivel Kumaravel, ${ }^{a}$ Sivakumar Thiripuranthagan, ${ }^{* a}$ Mani Durai, $^{\text {b }}$ \\ Elangovan Erusappan ${ }^{a}$ and Thanigaivel Vembulia
}

Correction for 'Catalytic transfer hydrogenation of biomass-derived levulinic acid to $\gamma$-valerolactone over Sn/Al-SBA-15 catalysts' by Sakthivel Kumaravel et al., New J. Chem., 2020, 44, 8209-8222, DOI: 10.1039/DONJ01288B.

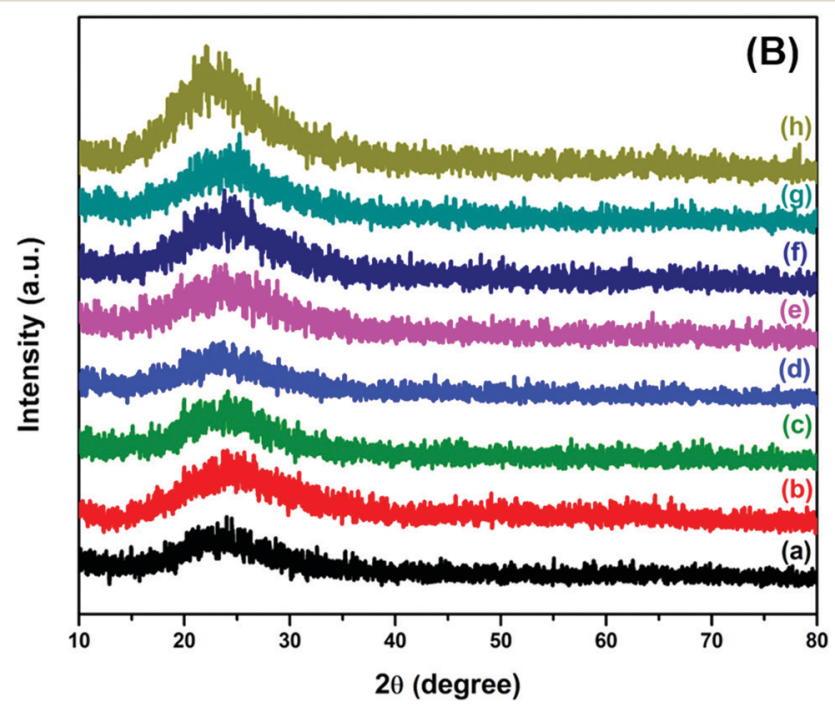

Fig. 1 (B) High angle XRD patterns of (a) SBA-15, (b) Al-SBA-15 (25), (c) Sn-SBA-15 (25), (d) Sn/Al-SBA-15 (10), (e) Sn/Al-SBA-15 (25), (f) Sn/Al-SBA-15 (50), (g) Sn/Al-SBA-15 (75) and (h) Sn/Al-SBA-15 (100) catalysts.

The Royal Society of Chemistry apologises for these errors and any consequent inconvenience to authors and readers.

\footnotetext{
${ }^{a}$ Catalysis Laboratory, Department of Applied Science and Technology, Anna University, Chennai, India. E-mail: tssivakumar@yahoo.com

${ }^{b}$ Centre for Nanoscience and Technology, Anna University, Chennai, India
} 